\title{
Tie2-dependent VHL knockdown promotes airway microvascular regeneration and attenuates invasive growth of Aspergillus fumigatus
}

\author{
Xinguo Jiang • Joe L. Hsu • Wen Tian • Ke Yuan • \\ Mark Olcholski • Vinicio de Jesus Perez • \\ Gregg L. Semenza • Mark R. Nicolls
}

Received: 18 April 2013 /Revised: 24 May 2013 / Accepted: 30 May 2013 /Published online: 25 June 2013

(C) The Author(s) 2013. This article is published with open access at Springerlink.com

\begin{abstract}
Microvascular ischemia and infections are associated with the development of chronic rejection following lung transplantation. The von Hippel-Lindau protein (VHL) controls protein levels of hypoxia-inducible factors (HIFs), regulates vascular repair, and improves tissue perfusion. Here, we studied the role of VHL in microvascular repair by orthotopically transplanting tracheas into mice with VHL haplodeficiency in Tie2 lineage cells. We showed that VHL haplodeficiency prolonged airway microvascular perfusion and promoted tissue blood flow through the production of the angiogenic factors, SDF-1 and angiopoietin 1. VHL-haplodeficient pulmonary endothelial cells exhibited increased angiogenic activity, resistance to serum deprivationinduced cell death, and enhanced microvascular repair. By contrast, in recipient mice with HIF- $1 \alpha$ deficiency in Tie2 lineage cells, microvascular repair was significantly diminished
\end{abstract}

X.J. and J.L.H. contributed equally to this manuscript.

Electronic supplementary material The online version of this article (doi:10.1007/s00109-013-1063-8) contains supplementary material, which is available to authorized users.

X. Jiang $\cdot$ J. L. Hsu $\cdot$ W. Tian $\cdot$ M. R. Nicolls

Medical Service, Veterans Affairs Palo Alto Health Care System, Palo Alto, CA, USA

X. Jiang $\cdot$ J. L. Hsu $\cdot$ W. Tian $\cdot$ K. Yuan $\cdot$ M. Olcholski $\cdot$

V. de Jesus Perez $\cdot$ M. R. Nicolls $(\triangle)$

Department of Medicine, Division of Pulmonary and Critical Care Medicine, Stanford University School of Medicine, 300 Pasteur Drive, Stanford, CA 94305-5110, USA

e-mail: mnicolls@stanford.edu

\section{G. L. Semenza}

Vascular Program, Institute for Cell Engineering, Departments of Pediatrics, Medicine, Oncology, Radiation Oncology, and Biological Chemistry, and McKusick-Nathans Institute of Genetic Medicine, Johns Hopkins University School of Medicine, Baltimore, MD, USA and suggested that recipient-derived HIF-1 $\alpha$ normally participates in the repair of alloimmune-mediated microvascular damage. To evaluate the translational impact of our findings, we compared VHL-haplodeficient mice with wild-type controls using a model of Aspergillus airway infection. In $83 \%$ of the VHL-haplodeficient recipients, Aspergillus fumigatus was noninvasive in contrast to $75 \%$ of wild-type mice in which the mold was deeply invasive. Our study demonstrated that stabilization of HIF-1 $\alpha$ in angiogenic cells, through Tie2 cell VHL haplodeficiency, promoted airway microvascular regeneration and vascular normalization and thereby minimized tissue ischemia and hypoxia. By also mitigating the virulence of $A$. fumigatus, a common pathogen and itself a risk factor for the development of lung transplant rejection, the selective enhancement of HIF- $1 \alpha$ expression has the prospect of offering several novel therapeutic effects to transplant recipients.

\section{Key message}

- Microvascular loss and prolonged ischemia occurs with acute rejection.

- Von Hippel-Lindau (VHL) protein controls hypoxia inducible factors (HIFs).

- In tracheal allografts, VHL haplodeficient Tie2 cells promote neovascularization.

- Reduced transplant ischemia limits Aspergillus invasion.

Keywords HIF-1 $\alpha$. Aspergillus fumigatus . VHL . Orthotopic tracheal transplant - Obliterative bronchiolitis . Chronic lung transplant rejection $\cdot$ Microvascular perfusion

\section{Introduction}

The main obstacle for long-term survival of lung transplant recipients is chronic rejection, histologically manifested as 
obliterative bronchiolitis (OB). Yet, the mechanisms by which OB develops remain poorly understood [1]. Recent autopsy studies have shown that airway microcirculatory dysfunction and ensuing small airway ischemia precede the onset of $\mathrm{OB}[2,3]$. Infections after lung transplantation also contribute to the development of OB [4]. Among these pathogens, infection with Aspergillus fumigatus results in a variety of diseases including: Aspergillus colonization, which contributes to OB, airway anastomotic infections, and invasive pulmonary aspergillosis [4-6]. For lung transplant recipients, infection with A. fumigatus represents a major cause of morbidity, with mortality rates as high as $82 \%$ [5-8]. In addition to the pathogen's putative role in chronic rejection, ischemic areas also may provide a substrate for fungal growth because A. fumigatus derives its nourishment from decaying organic matter. Thus, microvascular injury may be a central factor for the development of OB by promoting chronic allograft rejection and by fostering infections with OB-inducing microorganisms such as $A$. fumigatus.

In a murine orthotopic tracheal transplantation (OTT) model, we found that airway microvascular injury with associated tissue ischemia and hypoxia is apparent during acute rejection, which is followed by vascular regeneration and remodeling [9]. We further demonstrated that enhancing microvascular integrity during the acute phase of rejection preserved the airway architecture and attenuated chronic rejection [10]. How damaged airway microvasculature is repaired and regenerated during rejection episodes is incompletely understood. Additionally, it is not known whether enhanced airway microvascular regeneration can be achieved through augmenting the functional capacity of recipient-derived angiogenic cells and what role modulating microvascular ischemia may play in pathogen virulence.

The VHL gene encodes a multifunctional protein, pVHL, the substrate-binding subunit of an E3 ubiquitin ligase, which plays an important role in oxygen-sensing pathways by regulating the degradation of hypoxia-inducible factor (HIF)- $1 \alpha$ subunit [11]. In the presence of oxygen, two proline residues of HIF- $1 \alpha$ are hydroxylated by the prolyl hydroxylase PHD2, facilitating pVHL complex binding, to direct proteasomal degradation of HIF- $1 \alpha$. In hypoxic conditions, PHD2 is inactive and HIF- $1 \alpha$ is stabilized. HIF- $1 \alpha$ then dimerizes with the $\beta$ subunit, translocates to the nucleus, and induces gene transcription through binding to hypoxia response elements on enhancers of the oxygen-sensitive genes [12].

In the OTT model, damaged airway microvasculature is repaired by recipient-derived Tie2-expressing cells, comprised of three major subpopulations: cells of endothelial lineage, Tie2-expressing monocytes (TEM) of myeloid origin, and pericyte precursors of mesenchymal derivation [10]. HIF- $1 \alpha$ stabilization by adenosine-mediated signaling increases cellular adaptation to ischemic conditions [13]. In a mouse hind limb ischemia model, HIF-1 $\alpha$ gene therapy increased homing of bone marrow-derived angiogenic cells (BMDACs); combined with the induction of HIF- $1 \alpha$ in BMDACs, which promoted BMDAC survival in ischemic areas, this approach synergistically enhanced revascularization $[14,15]$. Endothelial cell (EC) PHD2 haplodeficiency normalizes tumor microvasculature structure and diminishes metastasis [16]. Together these studies suggest that increasing HIF expression in angiogenic cells promotes vascular repair and tissue normoxia.

We subsequently hypothesized that increasing HIF-1 $\alpha$ expression in Tie2-expressing cells would enhance airway microvascular regeneration. To achieve this, we specifically knocked down VHL in Tie2 lineage cells and examined how VHL haplodeficiency altered airway microvascular repair. We then evaluated the translational impact of increased tissue vascularization, using a model of Aspergillus tracheal infection. The main objective of this study was to determine whether airway microvascular repair and regeneration could be enhanced through increased expression of HIF- $1 \alpha$ in recipient-derived angiogenic cells and if this effect would modify the A. fumigatus host-pathogen interaction.

\section{Materials and methods}

\section{Mice}

All animal procedures were approved by Stanford's Administrative Panel on Laboratory Animal Care and/or the VA Palo Alto Institutional Animal Care and Utilization Committee. In addition, the Stanford University Applied Panel on Biosafety (protocol number 1007-MN0312) approved all microbiological experiments performed in this study. All mice including C57BL/6J (B6; H-2b), Balb/c (H-2d), C; 129S-Vhltm1Jae/J, B6.Cg-Tg (Tek-cre)12Flv/J; and B6.129-Hiflatm3Rsjo/J were purchased from the Jackson Laboratory.

To create VHL haplodeficiency in Tie2 lineage cells, mice with loxP sites on both sides of exon 1 of the VHL gene $\left(\mathrm{VHL}^{\text {loxP/loxP }}\right.$ ) were crossed with mice expressing Cre under promoter Tie2 (Tie2Cre mice). Tie2Cre(-)VHL(fl//) were used as control and Tie2Cre(+)VHL(fl/ ++$)$ mice as Tie2 lineage VHL haplodeficiency. For HIf-1 $\alpha$ knockout in Tie2 lineage cells, mice with HIF- $1 \alpha$ exon 2 floxed (HIF-1 $\alpha^{\text {loxP/loxP }}$ ) were also crossed with Tie2Cre mice. Tie2Cre(-)HIF $1 \alpha(\mathrm{fl} / \mathrm{fl})$ mice were used as control and Tie2Cre $(+) \mathrm{HIF} 1 \alpha(\mathrm{fl} / \mathrm{fl})$ as Tie2 lineage HIF$1 \alpha$ knockout. Those mice were used as transplant recipients.

Tracheal transplantation

$\mathrm{Balb} / \mathrm{c}$ mice were used as donors. Mice with transgenes as described above were used as recipients. Basic surgical procedures of tracheal transplantation were carried out as previously described [10]. Briefly, both donor and recipient mice 
were anesthetized with $50 \mathrm{mg} / \mathrm{kg}$ ketamine and $10 \mathrm{mg} / \mathrm{kg}$ xylazine. Five- to seven-ring tracheal segments were removed from donor mice that were matched for recipient age and sex. The donor tracheas were stored in PBS on ice before transplantation. A short incision was made in the midline of the neck region of the recipient. The strap muscles were then bluntly divided and pulled aside by a 3-0 suture, which allowed clear exposure of the laryngotracheal complex. After the recipient trachea was transected, donor trachea was sewn in with 10-0 nylon sutures, and the skin was closed with 5-0 silk sutures.

\section{A. fumigatus airway infection model}

A. fumigatus, 10AF (ATCC 90240), was used for all infections. Cultures were revived from long-term storage at $-80{ }^{\circ} \mathrm{C}$ by growth at $37^{\circ} \mathrm{C}$ on potato dextrose agar. Conidia were harvested by washing the surface of the agar plate with $0.05 \%$ Tween 80 in saline (vol/vol). Viability was assessed by quantitative plating of serial dilutions of the conidia onto Sabouraud dextrose agar plates. These were incubated for $48 \mathrm{~h}$ at $37{ }^{\circ} \mathrm{C}$ and the number of colonies counted. The suspension was then diluted to a concentration of $3-4 \times 10^{8}$ conidia per ml. Prior to infection, conidia were centrifuged $(5,000 \times g$ for $5 \mathrm{~min})$ and then washed twice with $1 \times$ PBS after centrifugation to remove excess Tween. Inoculation occurred via intratracheal injection (29-gauge insulin syringe), in which a $40-\mu l$ conidial solution was injected to two tracheal rings rostral to the cephalad anastomosis. After inoculation, animals were administered triamcinolone acetonide $(40 \mathrm{mg} / \mathrm{kg})$ subcutaneously. At day 2 after infection, all surviving mice were euthanatized using $\mathrm{CO}_{2}$ asphyxia.

Tissue preparation for perfusion studies and immunohistochemistry

For whole-mount tracheal microvascular analysis, mice were injected with $100 \mu$ of FITC-conjugated tomato lectin (Vector Laboratories) at a concentration of $1 \mathrm{mg} / \mathrm{ml}$. After $5 \mathrm{~min}$ of circulation, mice were perfused with $1 \%$ paraformaldehyde (PFA) diluted in PBS for about 2 min until the outflow of the solution turned clear. The tracheas were then harvested, put in $1 \%$ PFA for $1 \mathrm{~h}$ at $4{ }^{\circ} \mathrm{C}$, and washed three times with PBS. Whole tracheas were mounted on glass slides in Vectashield H-1200 mounting medium (Vector Laboratories). Blood perfusion unit measurement was carried out as described [17]. For assessment of the percentage of the perfused area, we examined the whole tracheal allograft (every cartilaginous and intercartilaginous region), each perfused area received a score of 1 and each nonperfused area received a score of 0 . The percentage was then calculated as follows: total score/total regions examined.
Frozen sections were used for other immunohistochemistry analysis. Trachea samples were snap-frozen in optimal cutting temperature (OCT) solution (Sakura Finetek) after harvest, and OCT-embedded samples were stored at $-80{ }^{\circ} \mathrm{C}$. Eight-micrometer sections were used for immunofluorescence staining. Anti-CD31 (1:200; BD Pharmingen) antibody was used to stain endothelial cells; anti-desmin (1:200; Millipore) antibody was used to stain pericytes; and anti-CD4 (1:200) and anti-CD8 (1:200; BD Pharmingen) were used to stain $\mathrm{CD} 4+$ and $\mathrm{CD} 8+\mathrm{T}$ cells, respectively. Photomicrographs were taken with a Zeiss LSM 510 laser scanning confocal microscope with Zeiss LSM Image Browser software.

Lung EC isolation and culture, Matrigel assay, scratch assay, and cell death assay

Mouse endothelial cell isolation Dynabeads ${ }^{\circledR}$ Sheep $\left(1 \times 10^{7}\right)$ were coated with anti-rat IgG (Invitrogen, cat. 110.35) then mixed with $1.5 \mu \mathrm{g}$ rat anti-mouse monoclonal CD31 $\mathrm{IgG}$ (BD Pharmingen). The beads and antibody were incubated at $2-8{ }^{\circ} \mathrm{C}$ overnight. Mouse lung tissues were minced into 1-2 $\mathrm{mm}$ pieces and then digested by adding $10 \mathrm{ml}$ of $1 \mathrm{mg} / \mathrm{ml}$ collagenase (Sigma) at $37^{\circ} \mathrm{C}$ for $1 \mathrm{~h}$. The cells were filtered through sterile $70 \mu \mathrm{m}$ nylon mesh and washed twice with $1 \times$ PBS. Coated Dynabeads ${ }^{\circledR}$ were added to cells and incubated for $30 \mathrm{~min}$ at $4{ }^{\circ} \mathrm{C}$ to allow binding to cells. The cells were washed in PBS and bead-bound cells were collected using a magnet and this step was repeated four times. Bead-bound cells were resuspended in DMEM with $20 \%$ FBS.

Matrigel assay Matrigel (Trevigen BME) was thawed on ice overnight and dispersed on 96-well plates ( $55 \mu$ l per plate) and allowed to polymerize for $30 \mathrm{~min}$ at $37{ }^{\circ} \mathrm{C}$. Lung ECs were seeded on the Matrigel at the density of 5,000 cells per well. Cells were incubated at $37{ }^{\circ} \mathrm{C}$ with $5 \% \mathrm{CO}_{2}$, and images were taken $6 \mathrm{~h}$ later. ImageJ software was used to determine total cellular cord length.

Scratch assay Lung ECs $\left(6 \times 10^{4}\right)$ were seeded on an Easy Slide (Millipore) until the formation of a confluent monolayer. Cells were then starved in a serum-free medium for $12 \mathrm{~h}$. Pipette tip (size of $200 \mu \mathrm{l}$ ) was used to scratch a straight line across the middle of the cell monolayer. Cell debris was washed off and cells with gap were incubated with $0.2 \%$ serum basal medium. Images were taken immediately after scratch and the same images of the same fields were obtained $6 \mathrm{~h}$ later. The rate of cell migration was calculated as the average percent wound closure from at least three independent experiments using ImageJ software. In brief, images were first converted to binary then threshold was adjusted and cell-covered area was highlighted over background. 
Percentage of cell-covered area was then calculated and denoted as percent wound closure. Serum deprivationinduced cell death was assessed by trypan blue exclusion assay. Endothelial cells were seeded in 24-well plates and cultured in the serum-free medium for $6 \mathrm{~h}$. Cell death was then assessed by trypan blue staining.

Hypoxia assessment, blood perfusion measurement, and vascular leakage study

Airway hypoxia was assessed by using Hypoxiprobe ${ }^{\mathrm{TM}}-1$, following manufacturer's protocol. Briefly, Hypoxiprobe ${ }^{\mathrm{TM}}$ 1 solution was injected at a dose of $60 \mathrm{mg} / \mathrm{kg}$ through peritoneum, and trachea was harvested and frozen in OCT 30 min later. After sectioning, anti-pimonidazole antibody was used to detect pimonidazole adducts which indicates tissue hypoxia. Blood perfusion measurement was carried out as we described [17]. Vascular leakage was analyzed after intravenous injection of $100 \mu \mathrm{l}$ of cy3-conjugated microsphere (\#R50) and $100 \mu \mathrm{l}$ FITC-lectin at a concentration of $1 \mathrm{mg} / \mathrm{ml}$. Ten minutes later, mouse was perfused with $1 \%$ PFA in PBS. Trachea was then harvested for whole-mount examination under confocal microscopy. The intensity of extravasated microsphere was calculated as described [18].

\section{Quantitative real time RT-PCR}

Tracheal samples were first incubated in RNAlater solution (Invitrogen) overnight at $4{ }^{\circ} \mathrm{C}$. Total RNA was then isolated using the QIAGEN Shredder and RNeasy Mini Kit (QIAGEN) following the manufacturer's protocol. Total RNA $(1 \mu \mathrm{g})$ was reverse transcribed with Moloney murine leukemia virus reverse transcriptase (Invitrogen) and $5 \mu \mathrm{M}$ random hexamer primers according to the manufacturer's instructions. Two microliters of one to ten diluted reverse transcription reactions was added to quantitative real timePCR with $5 \mu$ of $2 \times$ SYBR Green Master Mix (Applied Biosystems) and $100 \mathrm{nM}$ forward and reverse primers specific for the genes of interest in a total volume of $10 \mu \mathrm{l}$. Detection was carried out with the ABI Prism 7700 sequence detector (Applied Biosystems). SDS analysis software (Applied Biosystems) was used to analyze the data. $18 \mathrm{~S}$ mRNA expression was used to normalize gene expression for sample-to-sample variation in input and reverse transcription efficiency. The $2^{-\Delta \Delta \mathrm{Ct}}$ method was used to calculate fold changes. All primers used are shown in Supplemental Table 1.

Tissue preparation and evaluation for fungal infection

All tracheal samples were placed in paraffin blocks and cut longitudinally or transversely in $5 \mu \mathrm{m}$ sections through the entire tracheal segment. Grocott's methenamine silver (GMS) stain was used for each of these sections (Histotech laboratories). The most severe section was scored for each tracheal sample. Fungal infection was defined by the presence of hyphal elements on GMS stain in the tracheal segment. The degree of fungal burden was scored as follows: 0 , no fungal elements, 1 (minimal), fungal hyphae in less than $25 \%$ of the luminal area, 2 (mild) hyphae occluding 25 to $49 \%$ of the luminal area, 3 (moderate) hyphae 50 to $74 \%$ of luminal area, and 4 (severe) greater than $75 \%$ occlusion of the luminal area (Supplementary Fig. 3a). The depth of fungal invasion was graded: 1 (minimal), invasion of the epithelial layer; 2 (mild), invasion of the subepithelial layer; and 3 (moderate), invasion to the depth of the cartilaginous tracheal ring (Supplementary Fig. 3b).

\section{Statistics}

Statistical analysis was performed using two-tailed Student's $t$ test, with a significance level of $p<0.05$. Semiquantitative differences in fungal burden and depth of invasion were evaluated by a nonparametric Kruskal-Wallis test.

\section{Results}

$\mathrm{Tie}^{+}$cell VHL haplodeficiency prolongs airway microvascular perfusion and diminishes tissue hypoxia

The airway microcirculation is easily studied in major histocompatibility complex-mismatched orthotopic tracheal transplants; these are functional allografts through which the mouse breathes. This model system faithfully replicates lymphocytic bronchitis, a large airway precursor of chronic rejection (the bronchiolitis obliterans syndrome) [19]. We previously showed that following alloimmune-induced airway microvascular injury and tissue hypoxia, recipientderived Tie2-expressing cells are recruited to donor trachea and participate in vascular regeneration [10]. Upregulation of HIF- $1 \alpha$ promotes vascular reparative capacity of angiogenic cells $[14,15]$. Because VHL negatively regulates HIF- $1 \alpha$ protein levels, we hypothesized that downregulation of VHL would promote vascular reparative capacity of Tie2expressing cells through upregulation of HIF- $1 \alpha$ protein. To examine the role of VHL expressed in Tie $2^{+}$cells in airway microvascular repair, we conditionally knocked down VHL in Tie2 lineage cells to establish heterozygosity, as homozygous knockout results in embryonic lethality [20]. One allele VHL knockdown has been shown to efficiently decrease VHL protein expression in ECs [21]. Consistent with earlier findings [22, 23], VHL-haplodeficient lung ECs from Tie2Cre $(+)$ VHL(fl/ + ) mice expressed higher levels of HIF- $1 \alpha$ than ECs from Tie2Cre(-)VHL(fl//) mice (Supplementary Fig. 1). 
Tie2Cre(-)VHL(fl/+) recipients lost microvascular perfusion in tracheal transplants at day 14 posttransplantation and partial revascularization occurred by day 28 , as determined by confocal fluorescence microscopy after intravenous injection of FITC-lectin (Fig. 1a); early loss of perfusion is due to alloimmune rejection and revascularization occurs because of recipient-derived revascularization [10]. In contrast, tracheas transplanted into VHL-haplodeficient recipients showed significantly prolonged perfusion to day 18 posttransplantation and improved revascularization at day 28 (area perfused $\sim 40$ vs. $20 \%$ ) (Fig. 1b). Laser Doppler flowmetry (LDF) is another method of examining microvascular perfusion, providing a dynamic measurement of blood flow [17]. We demonstrated that microvascular perfusion of tracheas transplanted into VHL-haplodeficient mice was significantly higher than control mice from day 12 to day 28 following transplantation (Fig. 1c). Using pimonidazole staining to measure tissue hypoxia, we observed decreased tissue hypoxia in tracheas transplanted into VHL-haplodeficient recipients at both day 16 and day 28 posttransplantation (Fig. 1d). As Cre expression in this Tie2-Cre strain may affect $25 \%$ of bone marrow cells [24], we also evaluated the possibility that observed differences in airway perfusion were caused by diminished VHL expression in cells of hematopoietic origin participating in the alloimmune response. $\mathrm{As} \mathrm{CD} 4^{+}$and $\mathrm{CD} 8^{+}$ T lymphocytes have been previously demonstrated to mediate vascular injury [25], we examined infiltration of these cells in the tracheal allograft of VHL-haplodeficient and control animals. No significant differences were observed in the infiltration of $\mathrm{CD}^{+}$or $\mathrm{CD}^{+} \mathrm{T}$ cells in the donor tracheas (Supplementary Fig. 2a). Moreover, no significant differences were observed in mRNA expression levels of common pro-

\section{a}
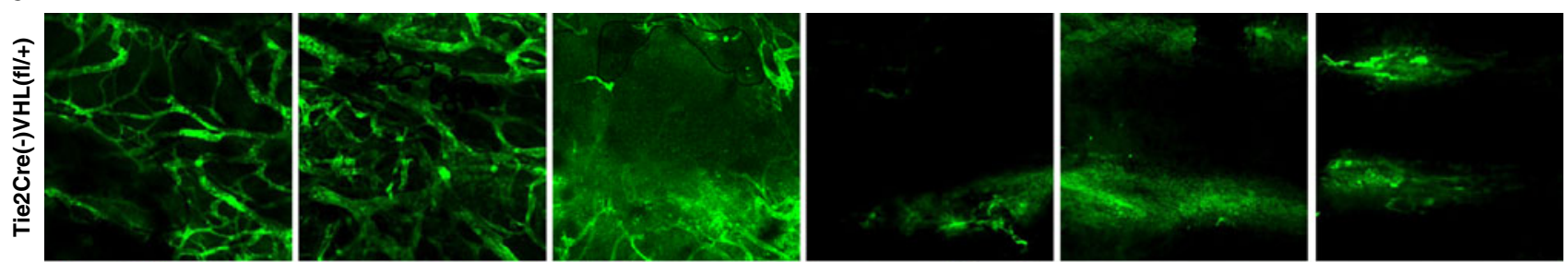

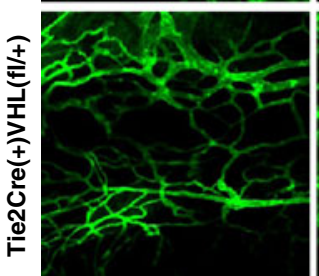

d12

b

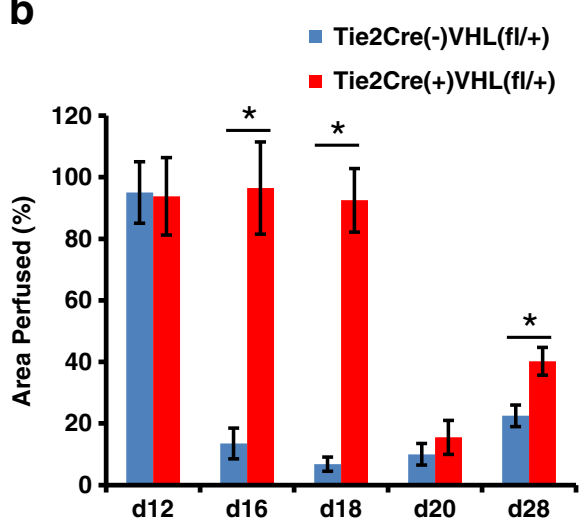

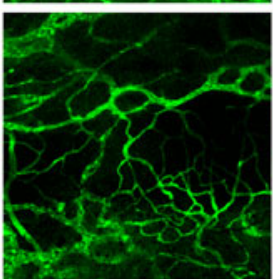

d16

C

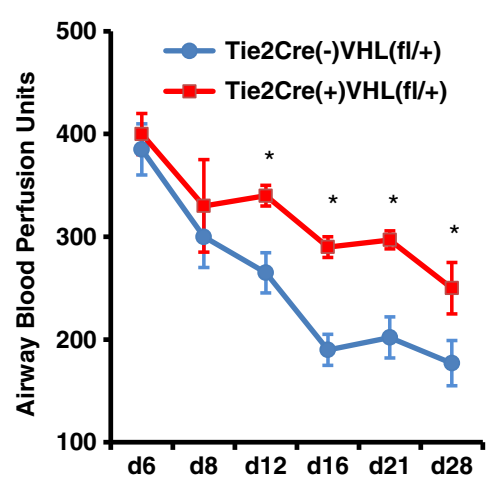

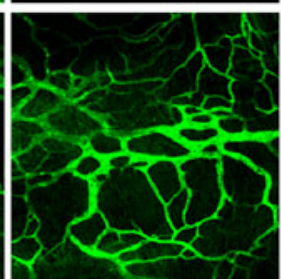

d18

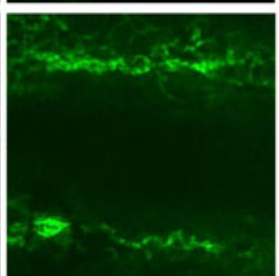

d20

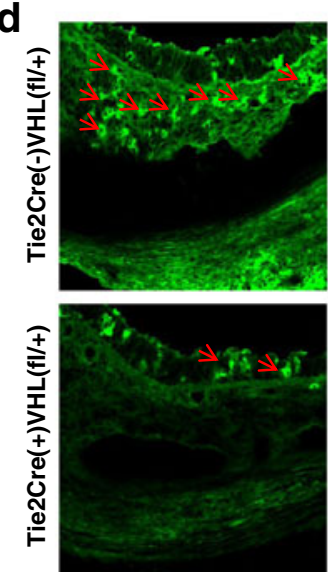

d16

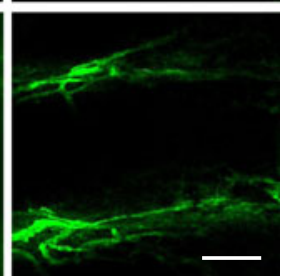

d28

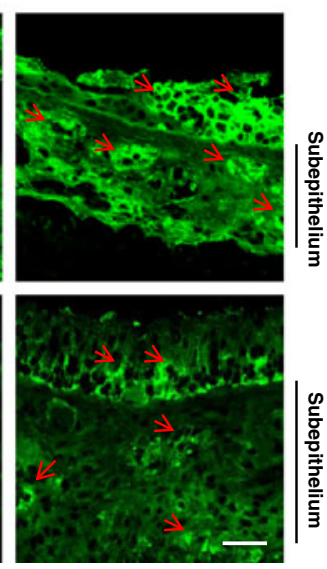

d28
Fig. 1 Recipient $\mathrm{Tie}^{+}$cell VHL haplodeficiency prolongs airway microvascular perfusion and diminishes tissue hypoxia. a Confocal microscopic FITC-lectin perfusion images showing microvascular perfusion of tracheas transplanted into control recipients with normal VHL expression compared with recipients with VHL haplodeficiency in Tie $2^{+}$cells. b Quantification of perfused airway microvasculature following transplantation $(n=4-6)$. c Airway blood perfusion measured by laser Doppler flowmetry in tracheas transplanted into recipients with or without VHL haplodeficiency ( $n=4-6$ per time point). d Pimonidazole staining (green, red arrows) in transplanted airways in both day 16 and day 28 showing decreased hypoxia in grafts transplanted into VHL-haplodeficient recipients. Scale bars, $100 \mu \mathrm{m}$ (a and d). Data are shown as means \pm SEM. ${ }^{*} P<0.05$ at individual time points, Student's $t$ test 
inflammatory chemokines (CXCL9, CXCL10, CXCL11, CCL5, MCP-1, and IFN- $\gamma$ ) (Supplementary Fig. 2b). Together these data suggest that the prolonged microvascular perfusion of tracheal transplants in Tie2Cre $(+) \mathrm{VHL}(\mathrm{fl} /+)$ recipients likely resulted from accelerated vascular repair by VHLhaplodeficient Tie $2^{+}$cells.

VHL-haplodeficient lung endothelial cells exhibit increased angiogenic activity and enhanced resistance to serum starvation-induced cell death

BMDACs with increased HIF-1 $\alpha$ expression survive longer in ischemic tissue and promote vascular repair in an ischemic hind limb model $[14,15]$. We hypothesized that increasing HIF-1 $\alpha$ expression through VHL knockdown would increase angiogenic potency of $\mathrm{Tie}^{+}$cells displaying endothelial lineage.
Lung ECs were isolated and cultured for experiments between passages 2 and 5. We first examined the effect of VHL loss on EC migration, an essential process for angiogenesis. Scratch assays showed that migration was markedly increased in VHL-haplodeficient ECs when cultured in media containing either 0.5 or $5 \%$ FBS (Fig. 2a, b). EC culture in Matrigel with media containing either 0.5 or $5 \%$ FBS revealed that VHL-haplodeficient cells exhibit significantly increased cord formation (Fig. 2c, d). As the capacity of EC survival in hypoxic tissue is essential for neoangiogenesis and vascular repair, we then evaluated the survival of VHL-haplodeficient ECs in serum deprivation studies. Using a trypan blue assay to assess cell death, we show that VHL-haplodeficient ECs were more resistant to serum deprivation-induced cell death (Fig. 2e). From these experiments, we conclude that VHL-haplodeficiency promoted a
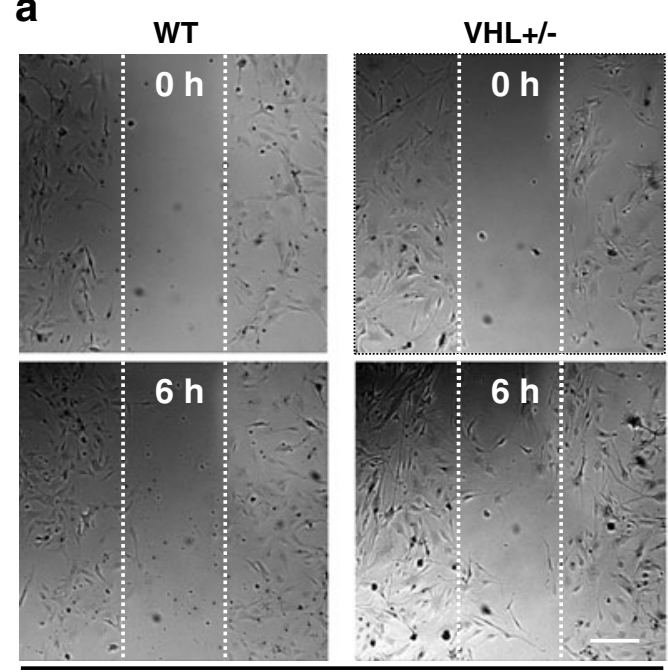

C
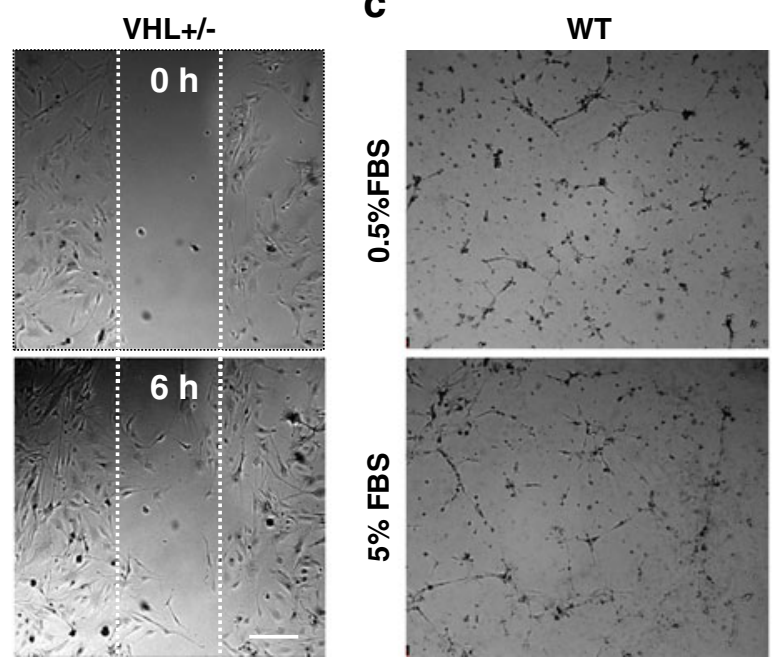
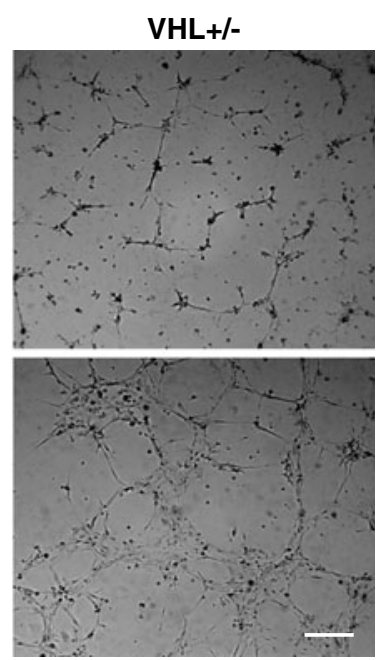

$5 \%$ FBS
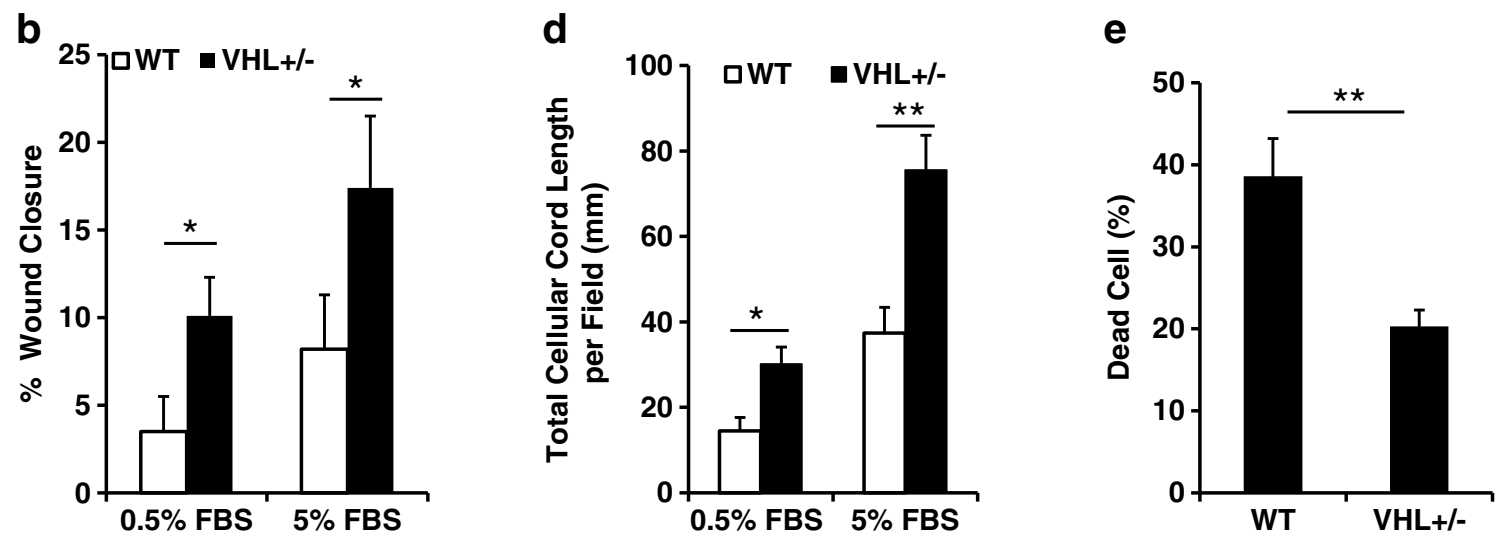

Fig. 2 VHL-haplodeficient lung endothelial cells exhibit enhanced angiogenic activity and increased resistance to serum deprivation-induced cell death. a Migration of wild type (WT) and VHLhaplodeficient $(V H L+/-)$ lung EC was assessed by scratch wound assay. Representative pictures were taken $6 \mathrm{~h}$ after scratch. b Percentage of wound closure was quantified $6 \mathrm{~h}$ after scratch at culturing conditions with 0.5 or $5 \%$ FBS. c Network/capillary formation of WT and VHL- haplodeficient ECs was assessed using a Matrigel assay. Representative images were taken $6 \mathrm{~h}$ after culturing in 0.5 or $5 \%$ FBS. d Quantification of network formation as measured by total cellular cord length for VHL-haplodeficient ECs in both 0.5 and $5 \%$ FBS conditions. e Cell death assessed by trypan blue assay. Experiments were performed three times. Scale bars, $300 \mu \mathrm{m}$ (a and c). Data are shown as means \pm SEM. $* P<0.05 ; * * P<0.01$, Student's $t$ test 
angiogenesis by increasing EC survival, migration, and cord formation.

VHL haplodeficiency increases angiogenic factor expression in ischemic airways

Expression of angiogenic growth factors and cytokines are closely associated with recruitment of circulating angiogenic cells and are essential for neovascularization. Based on the kinetics of microvascular perfusion of tracheas transplanted into recipients with different levels of VHL expression, mRNA was isolated from day 18 airway transplants, and expression of angiogenic factors, cytokines, and angiogenesis associated receptors was analyzed by quantitative RTPCR. Expression of HIF-1 $\alpha$, SDF-1, and ANGPT1 was significantly increased in airways transplanted into VHLhaplodeficient recipients, but no significant differences in

Fig. 3 Analysis of angiogenic cytokines and cognate receptors. a Real time RT-PCR analysis of angiogenic cytokines of day 18 airways transplanted into WT control or VHL-haplodeficient recipients. b Analysis of angiogenesisrelated receptors of day 18 airway allografts $(n=4-6)$. Data are shown as means $\pm \mathrm{SEM}$. $* P<0.05 ; * * P<0.01$, Student's $t$ test expression of ANPGT2, VEGF, or PLGF were observed (Fig. 3a). We then examined receptors commonly expressed on reparative ECs. Expression level of Tie2 is significantly higher in tracheas transplanted into VHL-haplodeficient recipients; other receptors such as CXCR4 and VEGFR2 were not significantly different between grafts transplanted into control and VHL-haplodeficient recipients (Fig. 3b). These data suggest that VHL knockdown in recipient Tie2 lineage cells promoted donor vascular repair by increasing the specific expression of angiogenic factors and recruitment (or survival) of vascular reparative cells.

VHL haplodeficiency improves microvascular function and maturation

Tissue perfusion is determined not only by vessel density, but also by the structural status of the investing microvasculature.
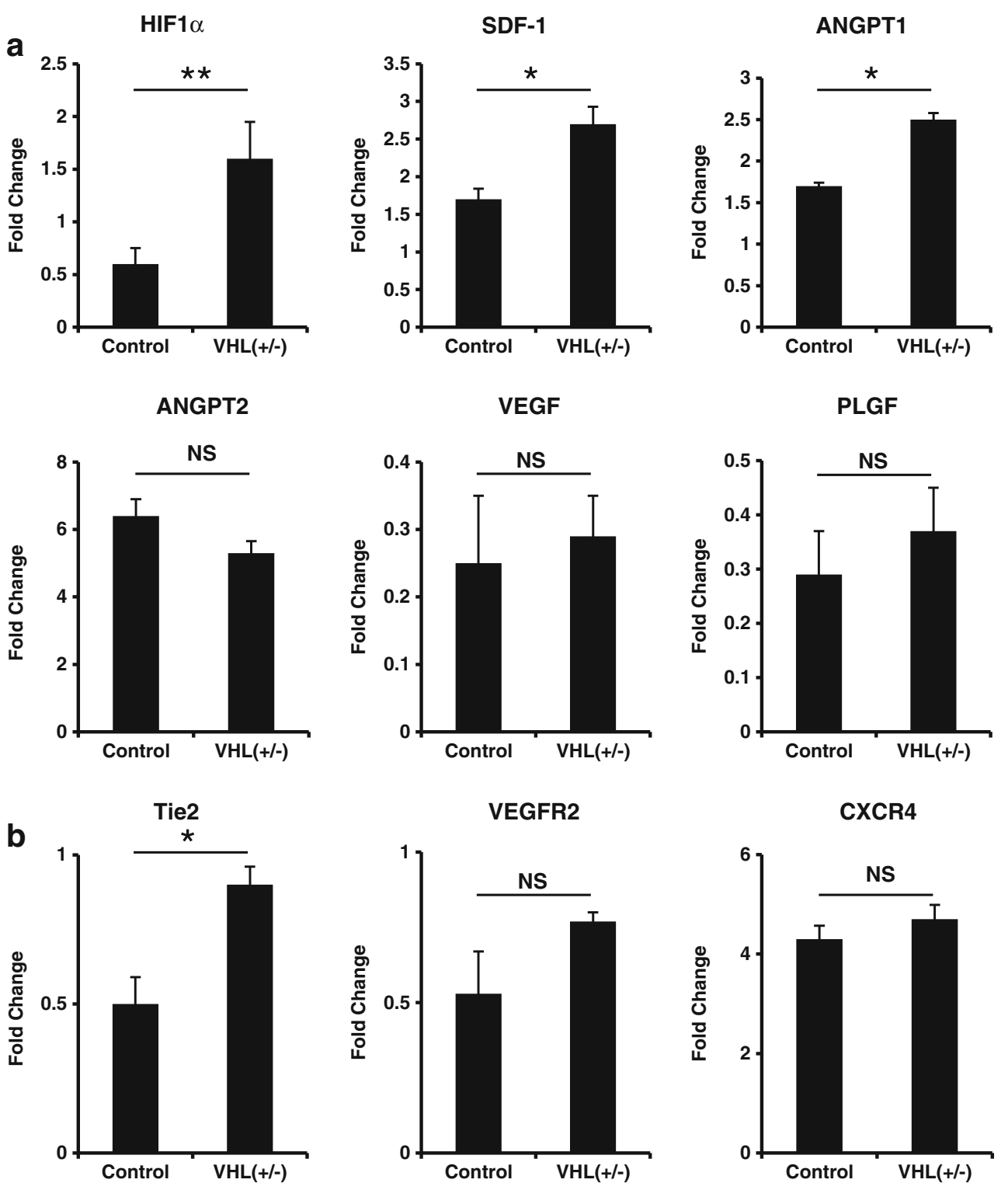
Leakiness of microvessels results in extravasated plasma, increased interstitial pressure, and compromised perfusion. Tumor vessels formed by PHD2-deficient ECs are more normalized compared with those formed by wild-type (WT) ECs [16]. To evaluate microvascular permeability in VHLhaplodeficient ECs compared with controls, we injected Cy3-conjugated microspheres and FITC-conjugated lectin into the circulatory system of animals under terminal anesthesia. Microsphere extravasation was reduced by $50 \%$ in airways transplanted into VHL-haplodeficient recipients at day 28 posttransplantation (Fig. 4a, b). Coverage of ECs by pericytes stabilizes vessels, and decreases plasma extravasation, resulting in improved perfusion [26]. Double staining with the EC marker CD31 and the mural cell (i.e., pericyte) marker desmin revealed more desmin-expressing cells covering vessels in grafts transplanted into VHL-haplodeficient recipients (Fig. 4c). Further pericyte coverage quantification showed about $30 \%$ increase in grafts from VHL-haplodeficient recipients (Fig. 4d). These structural studies indicate that VHL haplodeficiency enhanced airway vascular perfusion and alleviated tissue hypoxia in close association with improved vascular integrity.

Diminished airway microvascular regeneration and perfusion in Tie $2^{+}$cell HIF- $1 \alpha$ knockout recipients

To more specifically determine whether vascular regeneration of the tracheas was HIF- $1 \alpha$ dependent, mice bearing HIF- $1 \alpha$ knockout Tie2 lineage cells (Tie2Cre(+)HIF1 $\alpha(\mathrm{fl} / \mathrm{fl})$ ) and Tie2Cre(-)HIF $1 \alpha(\mathrm{fl} / \mathrm{fl})$ controls were used as allograft recipients. Airway graft perfusion in HIF-1 $\alpha$ knockout in Tie $2 \mathrm{Cre}(+) \mathrm{HIF} 1 \alpha(\mathrm{fl} / \mathrm{fl})$ recipient cells was decreased by $\sim 50 \%$ at both day 16 and day 21 (Fig. 5a, b). Examination of grafts by LDF confirmed decreased perfusion in tracheas transplanted into HIF-1 $\alpha$-deficient recipients (Fig. $5 \mathrm{c}$ ). These data suggest that HIF- $1 \alpha$ expression in Tie2 lineage cells is

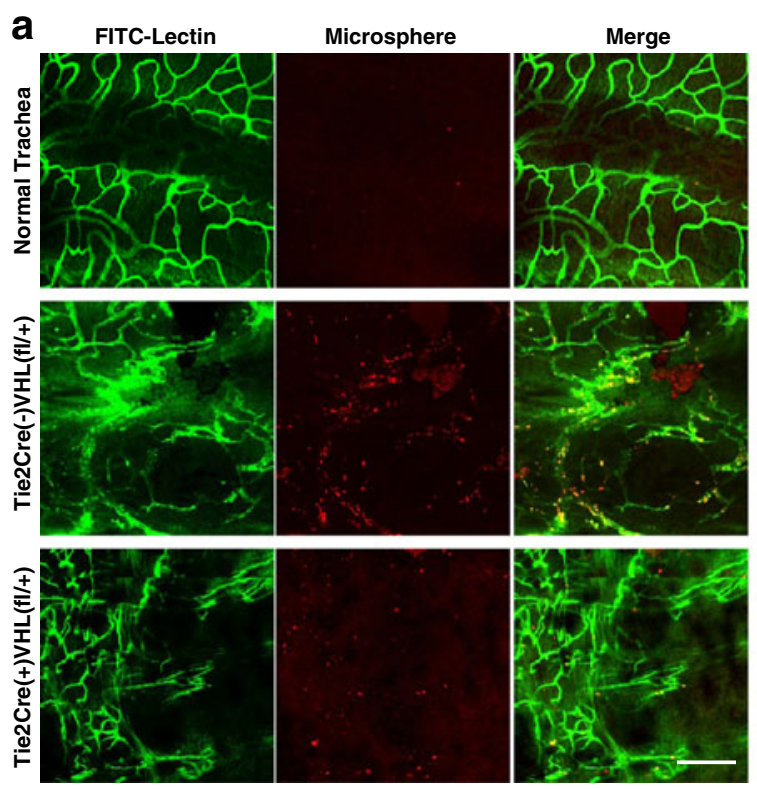

b

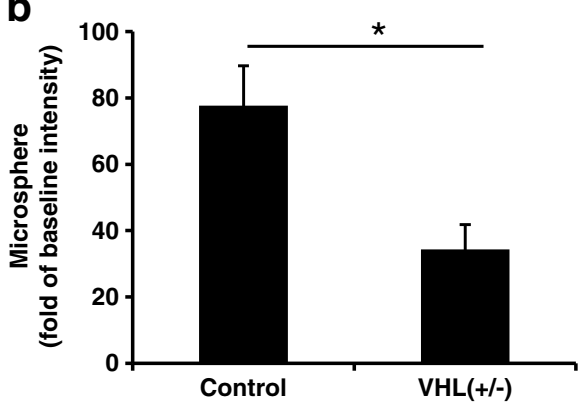

Fig. 4 Improved vessel function and maturation in airways transplanted into recipients with $\mathrm{Tie}^{+}$cell VHL haplodeficiency. a Representative confocal images showing extravasated $50 \mathrm{~nm}$ microsphere (red) and microvascular perfusion (green) in normal airways and airways transplanted into control or VHL-haplodeficient recipients at day 28. b Quantification of microsphere extravasation $(n=4-6)$. c CD31 (marker
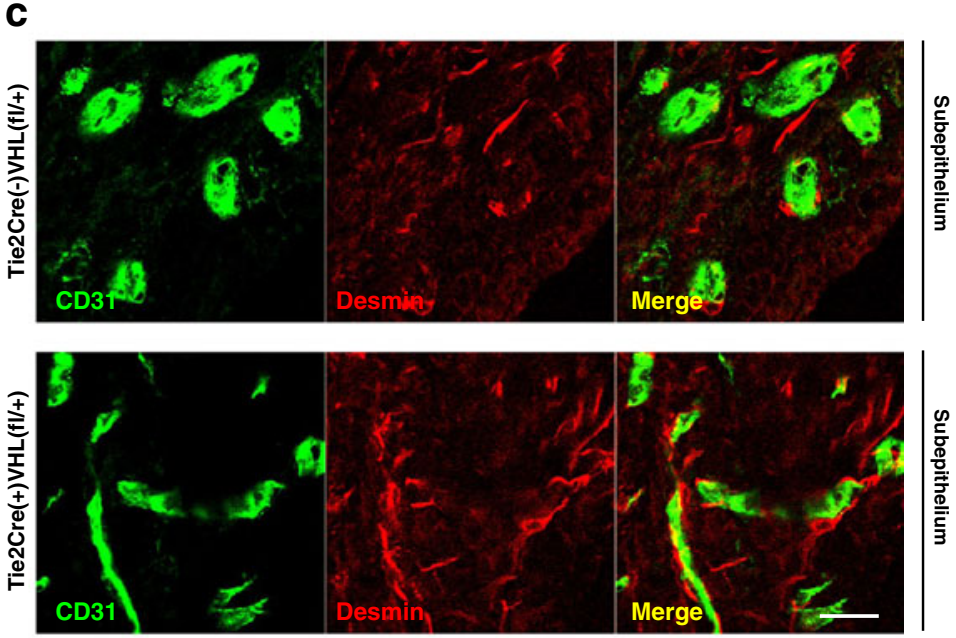

d

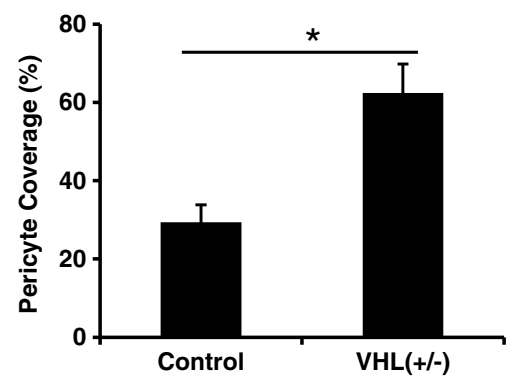

for ECs) and desmin (marker for pericytes) staining showed more complete pericyte-covered vessels in airways transplanted into VHLhaplodeficient recipients at day 28. d Quantification of pericyte coverage in the microvasculature of transplanted airways $(n=3-5)$. Scale bars, $100 \mu \mathrm{m}(\mathbf{a}), 20 \mu \mathrm{M}(\mathbf{c})$. Data are shown as means $\pm \mathrm{SEM},{ }^{*} P<0.05$, Student's $t$ test 
Fig. 5 Diminished microvascular perfusion of airways transplanted into recipient with HIF- $1 \alpha$ knockout in Tie2 lineage cells. a Representative FITC-lectin microvascular perfusion images at various time points posttransplantation. $\mathbf{b}$ Quantification of relative microvascular perfusion $(n=4$ 6). c Laser Doppler flowmetry analysis showing relative perfusion of tracheal transplants ( $n=4-6$ per time point). Scale bar, $100 \mu \mathrm{m}$ (a). Data are shown as means \pm SEM. ${ }^{*} P<0.05$, Student's $t$ test

a

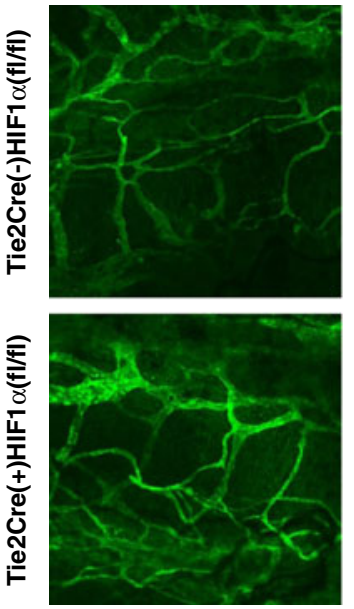

d8

b
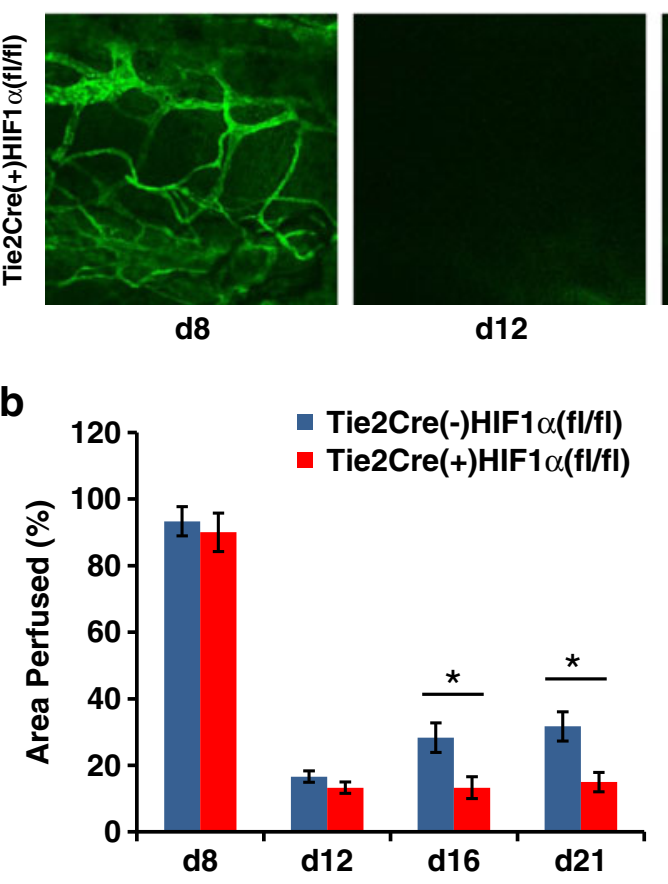

d12
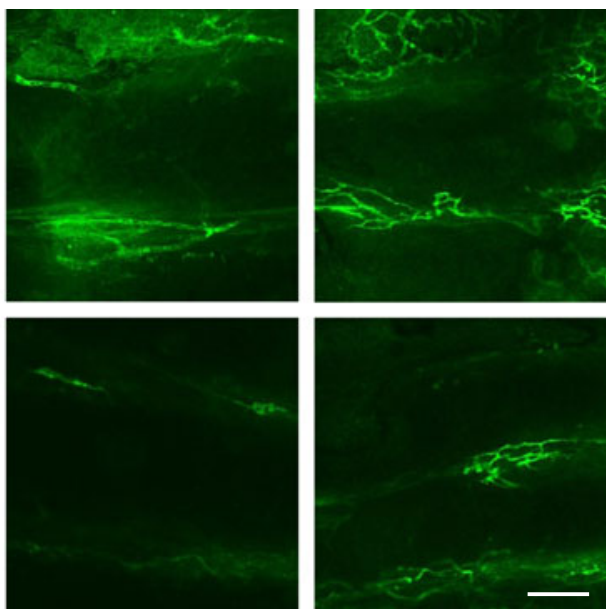

d16

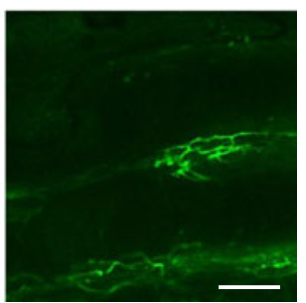

d21

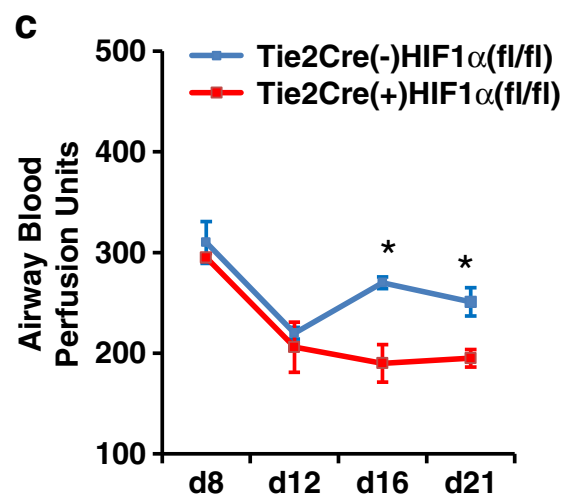

required for effective repair of airway microvasculature following allorejection-induced damage.

$\mathrm{Tie}^{+}$cell VHL haplodeficiency attenuates allograft invasion by $A$. fumigatus

To evaluate the translational impact of VHL haplodeficiencyassociated increased tissue perfusion, we compared Tie2Cre(-) VHL(fl/+) and Tie2Cre(+)VHL(fl/+) mice, using a standard Aspergillus tracheal infection assay. Mice were infected at day 16 posttransplantation and evaluated at day 18 for histopathological differences using GMS stain to detect fungi. Fungal burden and depth of invasion were graded on a semiquantitative scale (Supplementary Fig. 3a, fungal burden (0-4 scale), and Supplementary Fig. 3b, depth of fungal invasion (0-3 scale)). Allografts were evaluated with longitudinal or transverse sections (5- $\mu \mathrm{m}$ thickness) through the entire depth of the tracheal sample. On average, 420 transverse sections or 180 longitudinal sections were evaluated per tracheal sample. For each allograft, the section with the highest fungal burden or depth of invasion was used for scoring. Fungal burden was similar between $\mathrm{Tie} 2 \mathrm{Cre}(+) \mathrm{VHL}(\mathrm{fl} /+)$ and Tie2Cre(-)VHL(fl/+) mice (mean fungal burden score, 2.8 and 3.2, respectively, $P=0.5$ ) (Fig. 6a). In contrast, the degree of $A$. fumigatus invasion was significantly lower in VHLhaplodeficient recipients compared to control mice (mean depth of fungal invasion score, 0.3 and 1.9 , respectively, $P=0.04$ ) (Fig, 6b). In $83 \%(5 / 6)$ of the VHL-haplodeficient mice, A. fumigatus was noninvasive (depth of fungal invasion grade 0) (Fig. 6c), whereas in the control mice, $75 \%(6 / 8)$ showed a grade 2 (to subepithelial layer) or greater depth of invasion (Fig. 6d, e).

\section{Discussion}

We previously showed that recipient-derived Tie $2^{+}$cells are essential in the repair of damaged airway microvasculature following transplantation [10]. In the current study, we demonstrated that airway microvascular regeneration is promoted by VHL knockdown in Tie2 lineage cells. Microvascular perfusion is significantly prolonged in tracheas transplanted into recipients that are VHL-haplodeficient in Tie2 lineage cells. Although we cannot rule out the effect of VHLhaplodeficient hematopoietic cells, expression of common immune response- and inflammation-induced cytokines was not significantly altered in VHL-haplodeficient recipients, suggesting that extended microvascular perfusion likely 

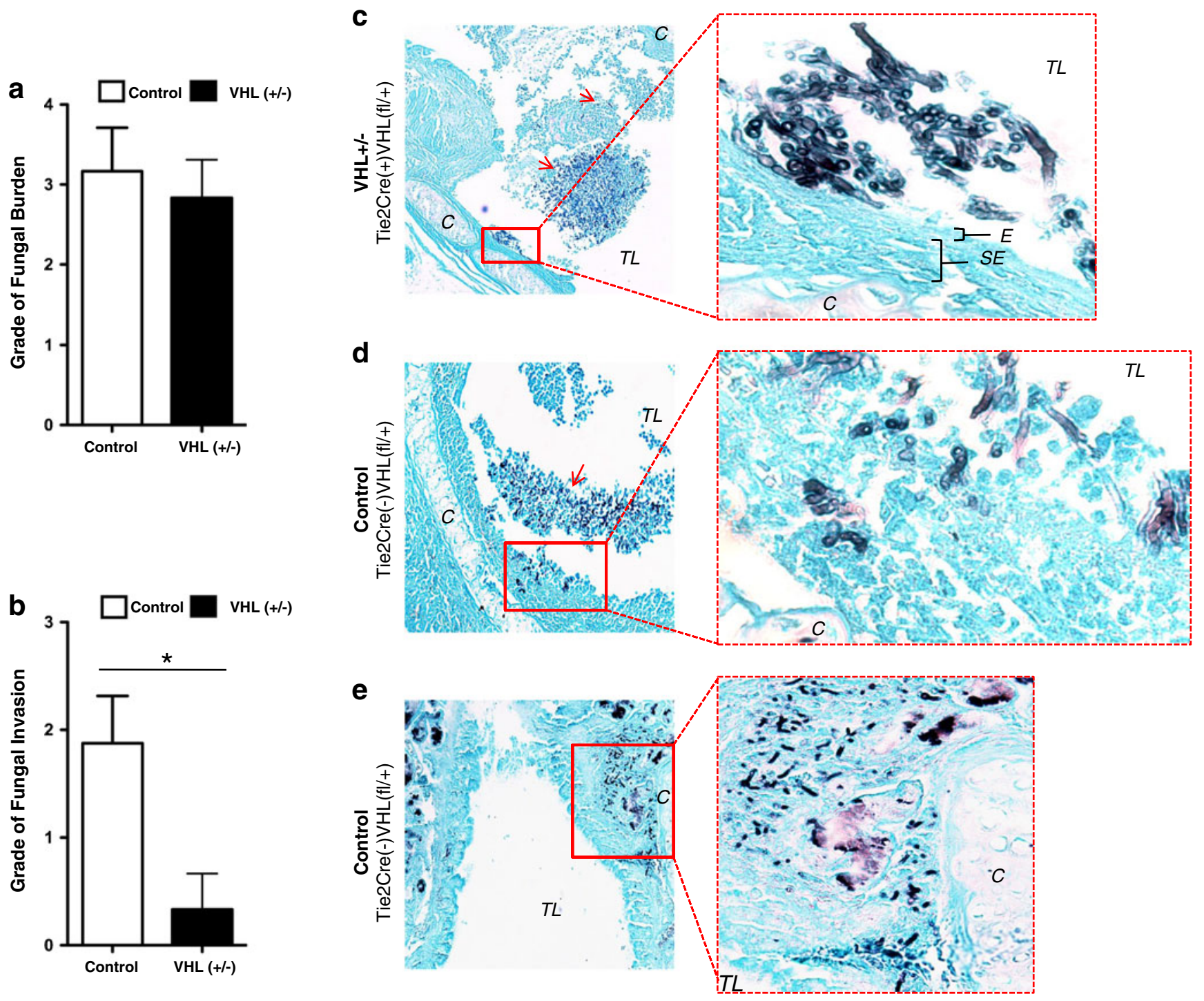

Fig. $6 \mathrm{Tie}^{+}$cell VHL haplodeficiency attenuates $A$. fumigatus invasion. All animals were infected with A. fumigatus on posttransplant day 16 and euthanized on day 18. A semiquantitative scoring system was used to grade the degree of fungal burden ( $0-4$ scale, Supplementary Fig. 3a) and depth of fungal invasion ( $0-3$ scale, Supplementary Fig. 3b). On average, 420 transverse sections or 180 longitudinal sections were evaluated and the section with the highest grade was used for scoring. a Degree of fungal burden, as measured on a semiquantitative scale $0-4$, by VHL expression status $(n=6)$. b Depth of fungal invasion, as measured on a semiquantitative scale by VHL expression status. Mean depth of invasion increased in control compared with VHLhaplodeficient mice $(n=8)$. Representative GMS sections of fungal invasion $(n=14)(\mathbf{c}-\mathbf{e})$. c Longitudinal section of A. fumigatus-infected
VHL-haplodeficient animal, displaying a high degree of fungal burden (grade 3) without evidence of epithelial invasion (grade 0$)(10 \times$ magnification), inset (100× magnification). d Transverse section of $A$. fumigatus-infected control animal with invasion to the depth of the subepithelial layer (grade 2) (10× magnification), inset (100× magnification). e Longitudinal section of A. fumigatus-infected control animal with invasion to the depth of the cartilaginous ring (grade 3) (10 magnification), inset (40× magnification). $C$ denotes cartilaginous ring, $E$ specifies epithelial layer, $S E$ specifies subepithelial layer, $T L$ denotes tracheal lumen ( $n=6-8$ animals/group). Red arrows denote fungal hyphae in lower magnification images. Data are shown as means \pm SEM. $* P<0.05$, nonparametric Kruskal-Wallis test

cell death, suggesting that these cells may have a survival advantage in the hypoxic microenvironment of the rejecting airway. Therefore, VHL haplodeficiency may increase airway microvascular repair by enhancing the angiogenic activity of ECs. It is not known whether VHL expression levels affect the function of TEMs, but as a subgroup of BMDACs, VHL haplodeficiency could conceivably reprogram TEM 
metabolism and augment their survival in an ischemic environment, as has been suggested [15].

Production of angiogenic factors in an ischemic microenvironment is associated with microvascular regeneration. We observed an increased expression of the angiogenic factor, SDF-1, in airways transplanted into recipients with VHL haplodeficiency. SDF-1 is a HIF-1 target gene product that is essential for the recruitment of CXCR4-expressing proangiogenic cells [10, 27]. Although CXCR4 and VEGFR2 expressions were not significantly different in airways transplanted into control and VHL-haplodeficient recipients, Tie2 expression was $\sim 2$-fold higher in airways transplanted into VHL-haplodeficient recipients. These data suggest that VHL haplodeficiency increases the expression of angiogenic factors, promoting recruitment and retention of angiogenic cells, and thus may establish a positive feedback loop to promote vascular repair.

In tracheas transplanted into VHL-haplodeficient recipients, we also showed a significant increase in ANGPT1 expression. ANGPT1 prevents the formation of the intercellular gaps in the endothelium, stabilizing the vasculature and protecting against leakage [28-30]. Although not required in quiescent mature vasculature, ANGPT1 functions as a protective factor, regulating responses to tissue injury and microvascular disease in diabetes [31]. In contrast, expression of ANGPT2 weakens endothelial-pericyte interactions, resulting in pericyte loss and vascular instability [32, 33]. It was recently shown that in conditions characterized by sustained inflammation, pericyte investment of the endothelium was required for the anti-leak actions of ANGPT1 [18]. Congruent with our findings for ANGPT1 in VHL-haplodeficient recipients, we also showed that regenerated vessels are less leaky and have more pericyte coverage. Together our data suggest that VHL haplodeficiency may increase vascular stability by regulating the expression levels of ANGPT1 and downstream signaling pathways, which stabilizes the vasculature through augmentation of mural cell coverage.

In recipients with HIF- $1 \alpha$ knockout in Tie 2 lineage cells, we demonstrated that microvascular repair is significantly diminished, suggesting that HIF- $1 \alpha$ expressed in Tie $2^{+}$cells is essential for repair of damaged microvasculature following alloimmune rejection. This finding is consistent with the previously established concepts that: (a) HIF-1 plays an essential role in vascular remodeling [34]; (b) EC HIF-1 $\alpha$ deficiency decreases cardiac capillary density following pressure overload [35]; and (c) HIF-1 deficiency impairs burn wound vascularization and homing of BMDACs [36]. We cannot rule out the possibility that EC-expressed HIF-2 $\alpha$ also may have contributed to airway microvascular repair and regeneration associated with VHL haplodeficiency. In fact, EC HIF- $2 \alpha$ has been associated with increased vascular stability in tumor xenograft microvasculature [16] and plays an important role in revascularization in limb ischemia and autochthonous skin tumor models [37]. Nevertheless, from our results, it is clear that loss of HIF- $1 \alpha$ alone in recipient Tie $2^{+}$cells was sufficient to significantly increase the duration of ischemia associated with allograft rejection.

Finally, we demonstrate that VHL haplodeficiency decreased the depth of A. fumigatus graft invasion when compared with infected WT controls, suggesting another therapeutic role for modulating HIF in lung transplant recipients. Although A. fumigatus is a facultative aerobe, it has the capacity to thrive in hypoxic conditions, an adaptation that may be critical for the mold's pathogenicity [38-41]. As $A$. fumigatus naturally grows in decaying organic matter, it is not surprising that improving microvascular perfusion and tissue health may lessen the invasive nature of the pathogen. Alternatively, increased expression of HIF- $1 \alpha$ may itself play a role in decreasing A. fumigatus invasion. Although the role of HIF in fungal pathogenesis is not well described, HIF plays a key role in mitigating bacterial pathogenesis $[42,43]$. For instance, the downregulation of HIF- $1 \alpha$ by Chlamydia is thought to provide a virulence advantage for the organism [43]. Another possibility is that VHLhaplodeficient and control recipients differed in their immune response to the fungus. However, as the two demonstrated baseline similarity in their expression of immune and inflammation-induced cytokines (Supplementary Fig. 2), differences in the immune response are not likely to account for the observed differences in fungal virulence. It is also notable that the degree of fungal burden was similar in VHL haplodeficient and WT control mice (Fig. 6a). Thus, the observed effect was likely a result of mitigating the pathogen's interaction with the host rather than lowering fungal burden, as might be observed with the use of antifungal agents.

In summary, we showed that the increased expression of HIF- $1 \alpha$ in recipient Tie 2 lineage cells through VHL knockdown promotes microvascular repair of tracheal allografts, which in turn leads to enhanced perfusion. VHL knockdown promotes vascular repair through several mechanisms, which include: enhancing the activity of angiogenic cells, as well as their recruitment, retention, and survival; increasing the expression of angiogenic growth factors; and stabilizing regenerated vessels. Moreover, we demonstrate the translational relevance of the current work by focusing on two factors associated with chronic rejection: ischemia and infection. Higher expression of HIF- $1 \alpha$ in the transplant recipient promotes microvessel integrity and may play an important role in modulating the host-pathogen interaction for A. fumigatus, a common pathogen and major clinical risk factor for the development of $\mathrm{OB}$ in lung transplant recipients $[44,45]$. This work complements our prior study [10] showing that enhanced HIF-1 $\alpha$ in donor tissue also facilitates vascular healing, suggesting that treatment of both graft and recipient with drug or gene therapy to induce HIF-1 
might be clinically beneficial. The actions of HIF- $1 \alpha$ are pleiotropic, and its actions contribute to both the promotion and resolution of inflammation in biological processes [46]. Additionally, HIF- $1 \alpha$ appears to exert multiple protective functions on mucosal surfaces (e.g., regulating defensins [47]). Given that the aging process impedes normal angiogenic cell mobilization and can be restored through the enhancement of HIF-1 activity [48], augmenting HIF-1 $\alpha$ activity may be particularly effective for preventing chronic rejection in elderly transplant recipients. In summary, this study suggests that targeting recipient-derived angiogenic cells may have value as a therapeutic approach for preventing chronic rejection through increasing airway microcirculation and modulating the pathogenicity of OBinducing microorganisms.

Acknowledgments This study was supported by NIH grant HL095686 and by a Veterans Affairs Merit Award BX000509 to M.R. Nicolls.

Conflict of interest The authors declare no conflict of interest.

Open Access This article is distributed under the terms of the Creative Commons Attribution License which permits any use, distribution, and reproduction in any medium, provided the original author(s) and the source are credited.

\section{References}

1. Weigt SS, Wallace WD, Derhovanessian A, Saggar R, Lynch JP, Belperio JA (2010) Chronic allograft rejection: epidemiology, diagnosis, pathogenesis, and treatment. Semin Respir Crit Care Med 31:189-207. doi:10.1055/s-0030-1249116

2. Luckraz H, Goddard M, McNeil K, Atkinson C, Charman SC, Stewart S, Wallwork J (2004) Microvascular changes in small airways predispose to obliterative bronchiolitis after lung transplantation. J Heart Lung Transplant 23:527-531. doi:10.1016/j.healun.2003.07.003

3. Luckraz H, Goddard M, McNeil K, Atkinson C, Sharples LD, Wallwork J (2006) Is obliterative bronchiolitis in lung transplantation associated with microvascular damage to small airways? Ann Thorac Surg 82:1212-1218. doi:10.1016/j.athoracsur.2006.03.070

4. Weigt SS, Copeland CA, Derhovanessian A, Shino MY, Davis WA, Snyder LD, Gregson AL, Saggar R, Lynch JP 3rd, Ross DJ et al (2013) Colonization with small conidia Aspergillus species is associated with bronchiolitis obliterans syndrome: a two-center validation study. Am J Transplant. doi:10.1111/ajt.12131

5. Singh N, Paterson DL (2005) Aspergillus infections in transplant recipients. Clin Microbiol Rev 18:44-69. doi:10.1128/CMR.18.1.4469.2005

6. Sole A, Morant P, Salavert M, Peman J, Morales P (2005) Aspergillus infections in lung transplant recipients: risk factors and outcome. Clin Microbiol Infect 11:359-365. doi:10.1111/j.1469-0691.2005.01128.x

7. Silveira FP, Husain S (2007) Fungal infections in solid organ transplantation. Med Mycol 45:305-320. doi:10.1080/13693780701200372

8. Singh N (2003) Fungal infections in the recipients of solid organ transplantation. Infect Dis Clin North Am 17:113-134, viii

9. Babu AN, Murakawa T, Thurman JM, Miller EJ, Henson PM, Zamora MR, Voelkel NF, Nicolls MR (2007) Microvascular destruction identifies murine allografts that cannot be rescued from airway fibrosis. J Clin Invest 117:3774-3785. doi:10.1172/JCI32311
10. Jiang X, Khan MA, Tian W, Beilke J, Natarajan R, Kosek J, Yoder MC, Semenza GL, Nicolls MR (2011) Adenovirus-mediated HIF1alpha gene transfer promotes repair of mouse airway allograft microvasculature and attenuates chronic rejection. J Clin Invest 121:2336-2349. doi:10.1172/JCI46192

11. Semenza GL (2012) Hypoxia-inducible factors in physiology and medicine. Cell 148:399-408. doi:10.1016/j.cell.2012.01.021

12. Bader HL, Hsu T (2012) Systemic VHL gene functions and the VHL disease. FEBS Lett 586:1562-1569. doi:10.1016/j.febslet.2012.04.032

13. Eckle T, Hartmann K, Bonney S, Reithel S, Mittelbronn M, Walker LA, Lowes BD, Han J, Borchers CH, Buttrick PM et al (2012) Adora2b-elicited Per2 stabilization promotes a HIF-dependent metabolic switch crucial for myocardial adaptation to ischemia. Nat Med 18:774-782. doi:10.1038/nm.2728

14. Rey S, Lee K, Wang CJ, Gupta K, Chen S, McMillan A, Bhise N, Levchenko A, Semenza GL (2009) Synergistic effect of HIF1alpha gene therapy and HIF-1-activated bone marrow-derived angiogenic cells in a mouse model of limb ischemia. Proc Natl Acad Sci U S A 106:20399-20404. doi:10.1073/pnas.0911921106

15. Rey S, Luo W, Shimoda LA, Semenza GL (2011) Metabolic reprogramming by HIF-1 promotes the survival of bone marrowderived angiogenic cells in ischemic tissue. Blood 117:4988-4998. doi:10.1182/blood-2010-11-321190

16. Mazzone M, Dettori D, Leite de Oliveira R, Loges S, Schmidt T, Jonckx B, Tian YM, Lanahan AA, Pollard P, Ruiz de Almodovar C et al (2009) Heterozygous deficiency of PHD2 restores tumor oxygenation and inhibits metastasis via endothelial normalization. Cell 136:839-851. doi:10.1016/j.cell.2009.01.020

17. Khan MA, Dhillon G, Jiang X, Lin YC, Nicolls MR (2012) New methods for monitoring dynamic airway tissue oxygenation and perfusion in experimental and clinical transplantation. Am J Physiol Lung Cell Mol Physiol 303:L861-L869. doi:10.1152/ajplung.00162.2012

18. Fuxe J, Tabruyn S, Colton K, Zaid H, Adams A, Baluk P, Lashnits E, Morisada T, Le T, O'Brien S et al (2011) Pericyte requirement for anti-leak action of angiopoietin-1 and vascular remodeling in sustained inflammation. Am J Pathol 178:2897-2909. doi:10.1016/ j.ajpath.2011.02.008

19. Sato M, Keshavjee S (2008) Bronchiolitis obliterans syndrome: alloimmune-dependent and -independent injury with aberrant tissue remodeling. Semin Thorac Cardiovasc Surg 20:173-182. doi:10.1053/ j.semtcvs.2008.05.002

20. Tang N, Mack F, Haase VH, Simon MC, Johnson RS (2006) pVHL function is essential for endothelial extracellular matrix deposition. Mol Cell Biol 26:2519-2530. doi:10.1128/MCB.26.7.2519-2530.2006

21. Champion KJ, Guinea M, Dammai V, Hsu T (2008) Endothelial function of von Hippel-Lindau tumor suppressor gene: control of fibroblast growth factor receptor signaling. Cancer Res 68:46494657. doi:10.1158/0008-5472.CAN-07-6003

22. Lange C, Heynen SR, Tanimoto N, Thiersch M, Le YZ, Meneau I, Seeliger MW, Samardzija M, Caprara C, Grimm C (2011) Normoxic activation of hypoxia-inducible factors in photoreceptors provides transient protection against light-induced retinal degeneration. Invest Ophthalmol Vis Sci 52:5872-5880. doi:10.1167/iovs.11-7204

23. Carroll VA, Ashcroft M (2006) Role of hypoxia-inducible factor (HIF)-1alpha versus HIF-2alpha in the regulation of HIF target genes in response to hypoxia, insulin-like growth factor-I, or loss of von Hippel-Lindau function: implications for targeting the HIF pathway. Cancer Res 66:6264-6270. doi:10.1158/0008-5472.CAN-05-2519

24. Lasater EA, Li F, Bessler WK, Estes ML, Vemula S, Hingtgen CM, Dinauer MC, Kapur R, Conway SJ, Ingram DA Jr (2010) Genetic and cellular evidence of vascular inflammation in neurofibromin-deficient mice and humans. J Clin Invest 120:859-870. doi:10.1172/JCI41443 41443

25. Khan MA, Jiang X, Dhillon G, Beilke J, Holers VM, Atkinson C, Tomlinson S, Nicolls MR (2011) CD4+ T cells and complement independently mediate graft ischemia in the rejection of mouse 
orthotopic tracheal transplants. Circ Res 109:1290-1301. doi:10.1161/ CIRCRESAHA.111.250167 CIRCRESAHA.111.250167

26. Jain RK (2005) Normalization of tumor vasculature: an emerging concept in antiangiogenic therapy. Science 307:58-62. doi:10.1126/ science.1104819

27. Ceradini DJ, Kulkarni AR, Callaghan MJ, Tepper OM, Bastidas N, Kleinman ME, Capla JM, Galiano RD, Levine JP, Gurtner GC (2004) Progenitor cell trafficking is regulated by hypoxic gradients through HIF-1 induction of SDF-1. Nat Med 10:858-864. doi:10.1038/nm1075 nm1075

28. Thurston G, Suri C, Smith K, McClain J, Sato TN, Yancopoulos GD, McDonald DM (1999) Leakage-resistant blood vessels in mice transgenically overexpressing angiopoietin-1. Science 286:2511-2514

29. Thurston G, Rudge JS, Ioffe E, Zhou H, Ross L, Croll SD, Glazer N, Holash J, McDonald DM, Yancopoulos GD (2000) Angiopoietin-1 protects the adult vasculature against plasma leakage. Nat Med 6:460-463. doi:10.1038/74725

30. Baffert F, Le T, Thurston G, McDonald DM (2006) Angiopoietin-1 decreases plasma leakage by reducing number and size of endothelial gaps in venules. Am J Physiol Heart Circ Physiol 290:H107H118. doi:10.1152/ajpheart.00542.2005

31. Jeansson M, Gawlik A, Anderson G, Li C, Kerjaschki D, Henkelman M, Quaggin SE (2011) Angiopoietin-1 is essential in mouse vasculature during development and in response to injury. $\mathrm{J}$ Clin Invest 121:2278-2289. doi:10.1172/JCI46322 46322

32. Maisonpierre PC, Suri C, Jones PF, Bartunkova S, Wiegand SJ, Radziejewski C, Compton D, McClain J, Aldrich TH, Papadopoulos N et al (1997) Angiopoietin-2, a natural antagonist for Tie2 that disrupts in vivo angiogenesis. Science 277:55-60

33. Pfister F, Wang Y, Schreiter K, vom Hagen F, Altvater K, Hoffmann S, Deutsch U, Hammes HP, Feng Y (2010) Retinal overexpression of angiopoietin-2 mimics diabetic retinopathy and enhances vascular damages in hyperglycemia. Acta Diabetol 47:59-64. doi:10.1007/ s00592-009-0099-2

34. Rey S, Semenza GL (2010) Hypoxia-inducible factor-1-dependent mechanisms of vascularization and vascular remodelling. Cardiovasc Res 86:236-242. doi:10.1093/cvr/cvq045 cvq045

35. Wei H, Bedja D, Koitabashi N, Xing D, Chen J, Fox-Talbot K, Rouf R, Chen S, Steenbergen C, Harmon JW et al (2012) Endothelial expression of hypoxia-inducible factor 1 protects the murine heart and aorta from pressure overload by suppression of TGF-beta signaling. Proc Natl Acad Sci U S A 109:E841-E850. doi:10.1073/ pnas.1202081109 1202081109

36. Sarkar K, Rey S, Zhang X, Sebastian R, Marti GP, Fox-Talbot K, Cardona AV, Du J, Tan YS, Liu L et al (2012) Tie2-dependent knockout of HIF-1 impairs burn wound vascularization and homing of bone marrow-derived angiogenic cells. Cardiovasc Res 93:162169. doi: $10.1093 / \mathrm{cvr} / \mathrm{cvr} 282 \mathrm{cvr} 282$

37. Skuli N, Majmundar AJ, Krock BL, Mesquita RC, Mathew LK, Quinn ZL, Runge A, Liu L, Kim MN, Liang J et al (2012) Endothelial HIF2alpha regulates murine pathological angiogenesis and revascularization processes. J Clin Invest 122:1427-1443. doi:10.1172/JCI57322 57322

38. Grahl N, Dinamarco TM, Willger SD, Goldman GH, Cramer RA (2012) Aspergillus fumigatus mitochondrial electron transport chain mediates oxidative stress homeostasis, hypoxia responses and fungal pathogenesis. Mol Microbiol 84:383-399. doi:10.1111/ j.1365-2958.2012.08034.x

39. Grahl N, Puttikamonkul S, Macdonald JM, Gamcsik MP, Ngo LY, Hohl TM, Cramer RA (2011) In vivo hypoxia and a fungal alcohol dehydrogenase influence the pathogenesis of invasive pulmonary Aspergillosis. PLoS Pathog 7:e1002145. doi:10.1371/journal.ppat. 1002145 PPATHOGENS-D-11-00223

40. Grahl N, Shepardson KM, Chung D, Cramer RA (2012) Hypoxia and fungal pathogenesis: to air or not to air? Eukaryot Cell 11:560 570. doi:10.1128/EC.00031-12 EC.00031-12

41. Hall LA, Denning DW (1994) Oxygen requirements of Aspergillus species. J Med Microbiol 41:311-315

42. Kontoyiannis DP (2010) Manipulation of host angioneogenesis: a critical link for understanding the pathogenesis of invasive mold infections? Virulence 1:192-196. doi:10.4161/viru.1.3.11380 11380

43. Nizet V, Johnson RS (2009) Interdependence of hypoxic and innate immune responses. Nat Rev Immunol 9:609-617. doi:10.1038/ nri2607

44. McDonald DM (2001) Angiogenesis and remodeling of airway vasculature in chronic inflammation. Am J Respir Crit Care Med 164:S39-S45

45. Zanini A, Chetta A, Imperatori AS, Spanevello A, Olivieri D (2010) The role of the bronchial microvasculature in the airway remodelling in asthma and COPD. Respir Res 11:132. doi:10.1186/ 1465-9921-11-132 1465-9921-11-132

46. Eltzschig HK, Carmeliet P (2011) Hypoxia and inflammation. N Engl J Med 364:656-665. doi:10.1056/NEJMra0910283

47. Kelly CJ, Glover LE, Campbell EL, Kominsky DJ, Ehrentraut SF, Bowers BE, Bayless AJ, Saeedi BJ, Colgan SP (2013) Fundamental role for HIF-1alpha in constitutive expression of human beta defensin-1. Mucosal Immunol. doi:10.1038/mi.2013.6 mi20136

48. Bosch-Marce M, Okuyama H, Wesley JB, Sarkar K, Kimura H, Liu YV, Zhang H, Strazza M, Rey S, Savino L et al (2007) Effects of aging and hypoxia-inducible factor-1 activity on angiogenic cell mobilization and recovery of perfusion after limb ischemia. Circ Res 101:1310-1318. doi:10.1161/CIRCRESAHA.107.153346 